\title{
High Efficiency Megawatt Motor Preliminary Design
}

\author{
Ralph H. Jansen ${ }^{1}$, Dr. Peter Kascak ${ }^{2}$, Dr. Rodger Dyson ${ }^{3}$, Dr. Andrew Woodworth" ${ }^{4}$, Dr. Justin Scheidler ${ }^{5}$, Andrew \\ D. Smith ${ }^{6}$, Erik Stalcup ${ }^{7}$, Thomas Tallerico ${ }^{8}$, Yaritza De Jesus-Arce ${ }^{9}$, David Avanesian ${ }^{10}$ \\ NASA Glenn Research Center, Brook Park, Ohio 44135 \\ Dr. Kirsten Duffy ${ }^{11}$ \\ University of Toledo, Toledo, Ohio 43606 \\ Paul Passe ${ }^{12}$, Gerald Szpak ${ }^{13}$ \\ Vantage Partners, Brookpark, Ohio 44142
}

\begin{abstract}
The High Efficiency Megawatt Motor (HEMM) is being designed to meet the needs of Electrified Aircraft Propulsion (EAP). A preliminary design has been completed and risk reduction activities are being conducted in three key areas: cryogenic cooler design, superconducting rotor coil design and manufacturing, and stator thermal management. The key objective of HEMM is to establish a motor technology which simultaneously attains high specific power (>16kW/kg ratio to electromagnetic weight) and high efficiency $(>98 \%)$ by judicious application of high temperature superconducting wire and integrated thermal management. Another important feature is to achieve the performance goals with an eye to aircraft integration constraints. An electromagnetic analysis was performed which shows that the proposed HEMM design meets the performance objectives if key current capability and mechanical constraints are achieved. The risk reduction activities are the first assessment of the key design features. The HEMM technology could be applied to a range of aircraft types that require megawatt level electrical power.
\end{abstract}

\section{Introduction}

$\mathrm{N}$ ASA Glenn Research Center is developing the High Efficiency Megawatt Motor (HEMM) with the goal of demonstrating a motor that has both high specific power $(16 \mathrm{~kW} / \mathrm{kg}$ electromagnetic weight goal) and high efficiency (99\% stretch goal). Electrified Aircraft Propulsion (EAP) is the target application for this electric machine. Requirements for the prototype machine are based on the Single-Aisle Turboelectric Aircraft with Aft Boundary Layer (STARC-ABL) concept. ${ }^{1}$ HEMM is a partially superconducting, synchronous wound field machine that can operate as a motor or generator (Figure 1). It combines a self-cooled, superconducting rotor with a semi-slotless stator, allowing the motor to achieve exceptional specific power and efficiency without incurring the external cooling weight penalty which commonly impacts superconducting machines. ${ }^{2}$ The combination of the described elements allows a motor to be built that essentially operates like any traditional (nonsuperconducting) motor when viewed externally as

${ }^{1}$ Technical Management, Aeronautics Mission Office, 21000 Brookpark Road, Brook Park, Ohio 44135, MS 162-3, AIAA Member.

${ }^{2}$ RSCH AST, Electrical Systems, Diagnostics and Electromagnetics Branch, non-member.

${ }^{3}$ AST, Direct Energy Conversion, Thermal Energy Conversion Branch, non-member.

${ }^{4} \mathrm{RSCH}$ AST, Electronics of Materials, Materials Chemistry and Physics Branch, AIAA Member.

${ }^{5}$ RSCH AST, Structural Dynamics, Rotating and Drive Systems Branch, non-member.

${ }^{6} \mathrm{RSCH}$ AST, Heat Transfer, Thermal Systems and Transport Processes Branch, non-member.

${ }^{7} \mathrm{RSCH}$ AST, Heat Transfer, Thermal Systems and Transport Processes Branch, non-member.

${ }^{8}$ RSCH AST, Structural Dynamics, Rotating and Drive Systems Branch, non-member.

${ }^{9}$ AST, Electrical Systems, Diagnostics and Electromagnetics Branch, non-member.

${ }^{10} \mathrm{AST}$, Electrical Systems, Diagnostics and Electromagnetics Branch, non-member.

${ }^{11}$ Senior Research Associate, Mechanical, Industrial and Manufacturing Engineering Department, AIAA Member.

${ }^{12}$ Systems Engineer, Mechanical Engineering Dept., non-member.

${ }^{13}$ Mechanical Engineer, Mechanical Engineering Dept, non-member. 
a system, however it incorporates superconductors on the rotor to create a strong airgap magnetic field that enables specific power and efficiency performance that cannot be achieved using normal conductors or permanent magnets.

The preliminary design of the HEMM motor has been completed and a ranked list of technical risks were created. A combination of analysis and testing is being conducted to reduce those risks.
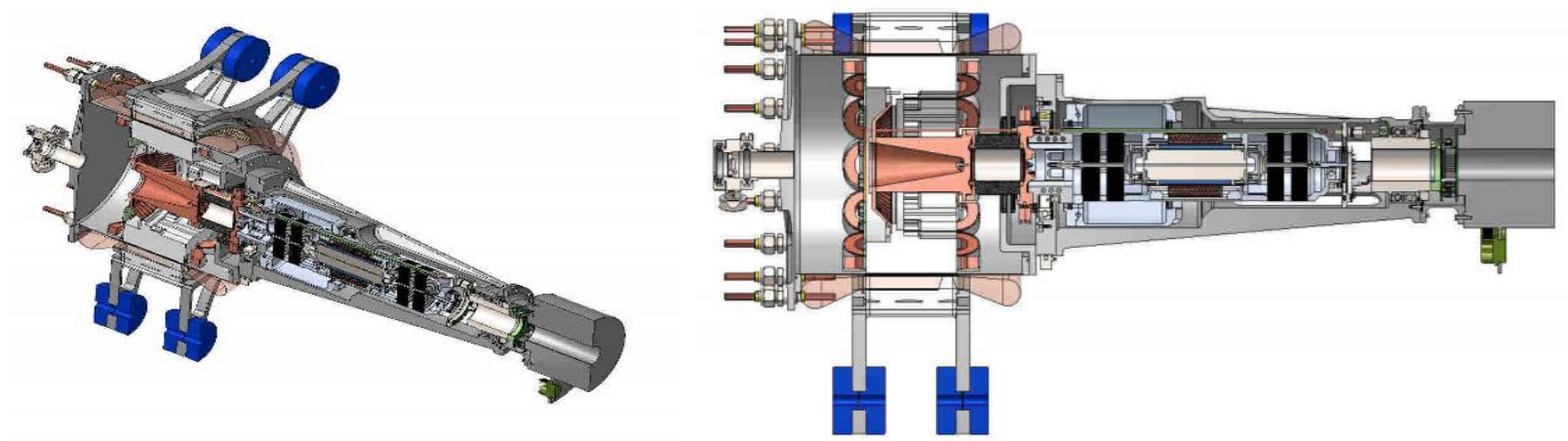

Figure 1. High Efficiency Megawatt Motor (HEMM) design

\section{A. HEMM Design Requirements}

The aeronautics industry has been challenged on many fronts to increase efficiency, reduce emissions, and decrease dependency on carbon-based fuels. Electrified Aircraft Propulsion (EAP), implemented through turboelectric, hybrid electric, or all electric propulsion has the potential to revolutionize the aviation industry. Previous studies have shown that the weight and efficiency of the power system must be beyond the current state-of-the-art to reduce fuel burn on the aircraft. $^{3,4}$ Additionally, the exploration of megawatt level components applies to a broad range of aircraft concepts ranging from fully turboelectric or electric systems in the nine passenger size, up to partially turboelectric systems for single-aisle aircraft. The HEMM requirements were derived based on the STARC-ABL single-aisle aircraft concept (Table 1).

Table 1. HEMM Prototype Requirements

\begin{tabular}{ll}
\hline \hline \multicolumn{1}{c}{ Requirement } & \multicolumn{1}{c}{ Rationale } \\
\hline The rated operating power shall be 1.4MW or greater & $\begin{array}{l}\text { From generator power requirements in 2016 STARC- } \\
\text { ABL Aviation paper }\end{array}$ \\
$\begin{array}{l}\text { The specific power of the electric machine shall be greater than 16 } \\
\mathrm{kW} / \mathrm{kg}\end{array}$ & $\begin{array}{l}\text { Combination of STARC-ABL sensitivity analysis and } \\
\text { Hybrid Gas Electric subproject goals }\end{array}$ \\
$\begin{array}{l}\text { The efficiency of the electric machine shall be greater than 98\% with } \\
\text { a stretch goal of } 99 \% .\end{array}$ & $\begin{array}{l}\text { Combination of STARC-ABL sensitivity analysis and } \\
\text { Hybrid Gas Electric subproject goals }\end{array}$ \\
$\begin{array}{l}\text { The rated operating speed shall be } 6800 \mathrm{RPM} \\
\begin{array}{l}\text { The thermal management approach shall be based on fluid cooling } \\
\text { with an inlet temperature of } 60^{\circ} \mathrm{C} \text { and the use of materials rated to }\end{array} \\
220^{\circ} \mathrm{C} \text { when possible. }\end{array}$ & $\begin{array}{l}\text { Bared on a UTRC NRA study of a parallel hybrid } \\
\text { single-aisle aircraft with a 1MW motor connected to } \\
\text { each turbofan. }\end{array}$ \\
\hline
\end{tabular}

\section{HEMM Preliminary Design}

\section{A. Motor Design}

Permanent magnet, switched reluctance, induction, and wound field machine types are being considered for aircraft propulsion electrical systems. Typically, studies focus on specific power as the key differentiating metric for the selection of the motor type. However, other metrics such as efficiency, speed matching with a load or source, ability to shut down in a fault condition, thermal management constraints, and electrical system integration considerations are equally important for overall system performance.

HEMM is a wound field machine type with a superconducting rotor and normal operating temperature stator. 5,6,7 This configuration was selected based on initial trade studies for balanced performance. Another important operational benefit of the wound field machine is that it can be shut down by de-energizing the field winding, unlike the permanent magnet machine; de-energizing removes force from the drive shaft without the need for mechanical 
decoupling. In this case, the stator of the HEMM is designed to use a typical fluid or air cooling loop. For the prototype machine, it is anticipated that the cooling loop will be a dielectric oil with an input temperature of $60^{\circ} \mathrm{C}$. The top level parameters of the motor design are shown in Table 2, and the cross section is shown in Figure 2.

Typically, machines have to trade specific power and efficiency; however, both are crucial for a successful design. ${ }^{2,3}$ The HEMM has the potential to achieve high specific power and efficiency goals simultaneously because it utilizes superconducting wires in the rotor, which provide a much higher air gap field capability than either permanent magnets, normal wound field conductors, or an induction rotor configuration. Employing superconducting coils provides a dramatic improvement in magnetic field generated because the direct current resistance is zero in the superconductor at the correct operating conditions. However, superconducting machine applications have been limited because superconductors require cryogenic temperatures to operate, which typically require a separate cryogenic fluid cooling system, adding mass, volume, and complexity to the overall system.

The HEMM incorporates a cryocooler in the rotor of the machine, and connects the cold tip of the cryocooler to the superconducting coils conductively, thereby eliminating the need for any external cryogenic equipment or any cryogenic fluids. A cryocooler is being designed that can lift $50 \mathrm{~W}$ of heat from a $50 \mathrm{~K}$ cold tip and reject to a $300 \mathrm{~K}$ ambient environment. This cryocooler is also intended to be light weight $(<10 \mathrm{~kg})$, small diameter $(<100 \mathrm{~mm})$, and capable of withstanding 6800RPM rotation about its central axis such that it can be integrated in the shaft of the HEMM. Incorporation of the cryocooler and its related subcomponents within the motor will enable the HEMM to interface with the aircraft in the same way as any standard electric machine, avoiding the additional mass, volume, and infrastructure which would be required with a traditional superconducting machine.

Table 2. Motor Design Parameters

\begin{tabular}{ll}
\hline \hline Parameter & Value \\
\hline Motor & Wound field synchronous \\
Rated Power & $1.4 \mathrm{MW}$ \\
Rated Speed & $6800 \mathrm{RPM}$ \\
Rated Voltage & $1200 \mathrm{~V}$ \\
Rated Current & $360 \mathrm{~A}$ \\
Layout & \\
Poles & 12 pole \\
Phases & 9 \\
\hline
\end{tabular}

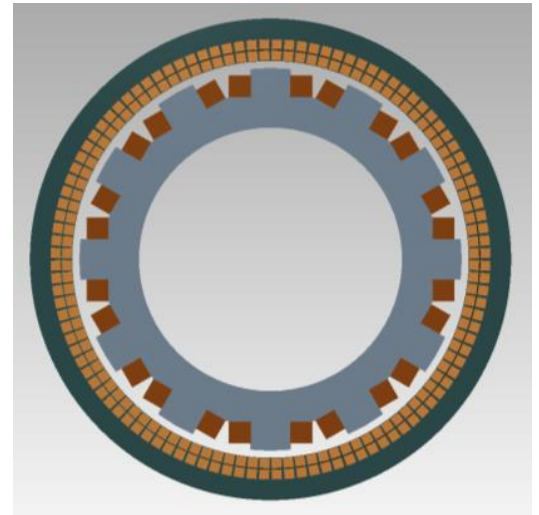

Figure 2. Motor Cross Section

\section{B. Thermal Conditions}

The thermal conditions are key to estimating the performance of any motor. Temperature conditions used for the electromagnetic analysis of the HEMM machine were found through separate thermal finite analysis, and imposed as fixed temperatures for this work. Temperatures of key components are shown in Table 3.

The stator temperature analysis was done by finding anisotropic thermal conductivities for the windings based on the properties of the Litz wire and the potting compound, using the losses estimates from the electromagnetic analysis, and building a simplified thermal FEA model which included the geometric relationships of the motor and the boundary conditions imposed by the liquid cooling loop. Significant uncertainty exists in the estimation of the effective thermal conductivity of the potted Litz wire; tests are planned to reduce that uncertainty.

The rotor temperature analysis was done by estimating the heat load and the cryocooler performance, and building a simplified thermal FEA model to represent the geometry and boundary conditions. The estimated rotor heat load included radiation heat transfer, heat leak through the torque tube, heat leak through the power leads for the rotor winding, windage losses, and rotor core losses. Rotor core loss is particularly difficult to estimate, because the eddy current and hysteresis losses are induced by high order

\section{Table 3. Key Component Temperatures}

\begin{tabular}{lcc}
\hline \hline Component & Temperature $\left({ }^{\circ} \mathrm{C}\right)$ & Temperature $(\mathrm{K})$ \\
\hline Stator core & 60 & 333 \\
Stator windings & 135 & 408 \\
End turns & 135 & 408 \\
Rotor core & -213 & 60 \\
Rotor coils & -213 & 60 \\
\hline
\end{tabular}


multiples of the stator fundamental frequency, and test data for the magnetic material at these frequencies and temperatures does not exist.

\section{Electromagnetic Performance Estimate}

An initial electromagnetic performance estimate for the HEMM motor was performed using a commercial sizing code which combines 2D electromagnetic finite analysis with a set of motor design rules. Key parameters are used to define the operating conditions of the motor, the rotor and stator magnetic circuit, and the rotor and stator windings. The trade space was explored through manual iteration, in which additional modeling and FEA modeling packages were used to perform solid modeling of the motor; detailed 3D thermal, stress, electromagnetic analysis; and cryocooler sizing. Mass and performance estimates were made using the motor parameters described in Section II.

\section{A. Torque Estimate}

Estimated torque as a function of speed is shown in Figure 3. Torque is current limited and is essentially constant at $2000 \mathrm{~N}-\mathrm{m}$ from zero speed to the rated speed of 6800RPM. Above the 7500 RPM the torque is voltage limited and begins to drop off.

\section{B. Electromagnetic Mass Estimate}

The electromagnetic mass estimate is shown in Table 4. The core mass estimates are based on the use of a cobalt-iron alloy. The superconducting rotor coil mass is estimated using the properties of the copper substrate because that is the dominant wire mass component. For this design approximately $70 \%$ of the electromagnetic mass is in the core, and $30 \%$ of the mass is in the rotor and stator windings. Litz wire mass is estimated using a packing factor. The total electromagnetic mass is estimated to be $74.2 \mathrm{~kg}$. A $10 \%$ mass margin is added to account for design and analysis uncertainties.

\section{Loss Estimate}

A summary of the loss estimation at rated operating conditions is shown in Table 5.

Electromagnetic losses were calculated using a combination of the above-described commercial motor sizing code and spreadsheet calculations for stator winding proximity losses. The proximity losses in this machine are significant, because the stator winding is directly exposed to a significant $\mathrm{AC}$ magnetic field imposed by the rotor field. As a result Litz wire is required to minimize these losses, at the expense of copper packing factor in the stator.

Other losses were calculated using a combination of in-house codes for cryocooler power estimation, and spreadsheet calculations for proximity and bearing losses. Additional losses were calculated separately to account for the total loss in the machine.

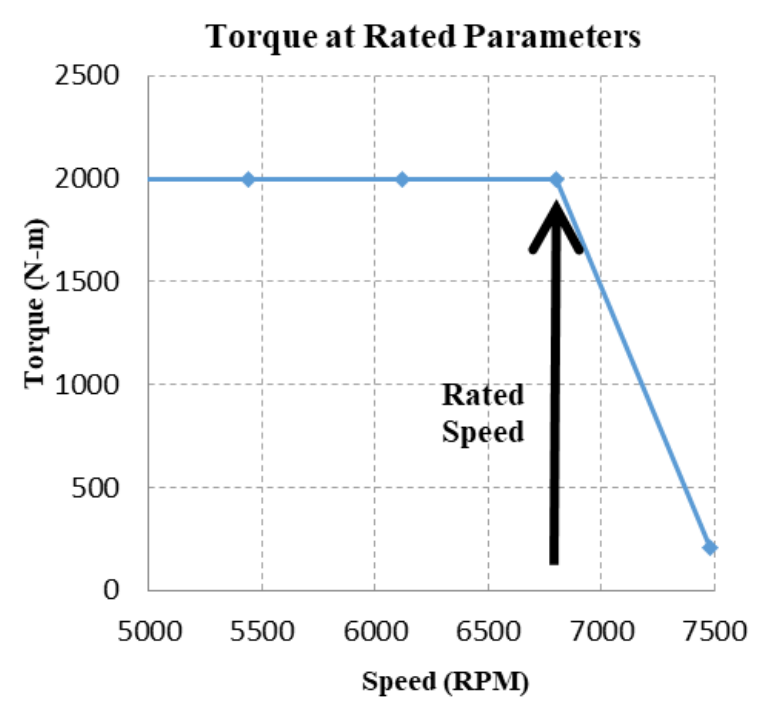

Figure 3. Torque at Rated Parameters

Table 4. Mass Estimate

\begin{tabular}{lc}
\hline \hline Component & Mass $(\mathrm{kg})$ \\
\hline Stator core & 21.5 \\
Stator winding & 13.77 \\
Rotor core & 29.7 \\
Rotor coils & 9.4 \\
Total Electromagnetic Mass & 74.4 \\
& \\
Total Electromagnetic Mass $(+10 \%$ & 81.9 \\
margin) & \\
\hline
\end{tabular}

Table 5. Loss Estimate

\begin{tabular}{lc}
\hline \hline Component & Loss $(\mathrm{kW})$ \\
\hline Electromagnetic Losses & 9.3 \\
Stator Core & 3.9 \\
Stator winding (I^2R) & 4.6 \\
Stator winding proximity & 0.8 \\
Rotor core & 0.009 \\
Rotor coils & 0 \\
& \\
Other Losses & 4 \\
Cryocooler Power & 2 \\
Bearings & 1 \\
Vacuum Seals & 1 \\
Total Losses & 13.5 \\
Total Losses(+20\% margin) & 16.2 \\
\hline
\end{tabular}


The estimated total losses are $13.5 \mathrm{~kW}$, comprised of $9.3 \mathrm{~kW}$ electromagnetic loss, $1 \mathrm{~kW}$ due to bearing drag, $2.5 \mathrm{~kW}$ to power the cryocooler, and $1 \mathrm{~kW}$ due to seal drag. A $20 \%$ loss estimate margin is added to account for design and analysis uncertainties, resulting in a total loss with margin of $16.2 \mathrm{~kW}$.

\section{Rated Performance Estimate vs Requirements}

The estimated rated performance of HEMM meets or exceeds the requirements set forth in the beginning of the project (Table 6).

\section{E. Risk Analysis}

A risk analysis was conducted to identify and rank the technical risks. Investments in risk reduction tests were made on this basis. The risks can be grouped into those related to the rotating cryogenic cooler, those related to the rotor, and those related to the stator. We have initiated a technical risk reduction effort based on a combination of analysis and testing. Most of these efforts address multiple risks. A list of the risks and the resulting Risk Matrix are presented in Table 7, and the Risks, Consequences, and Background are summarized in Table 8.

Table 7 - Ranked Risks

\begin{tabular}{cl}
\hline \hline $\begin{array}{c}\text { Risk } \\
\text { Number }\end{array}$ & Risk \\
\hline 2 & Rotor Superconducting Coil Stress \\
3 & Rotor Heat Load \\
7 & Slotless Stator Coil Manufacturing \\
1 & Cryo-cooler operation at speed \\
4 & Rotor Superconducting Coil \\
5 & Manufacturing \\
6 & Slotless Stator Coil Cooling \\
\hline
\end{tabular}
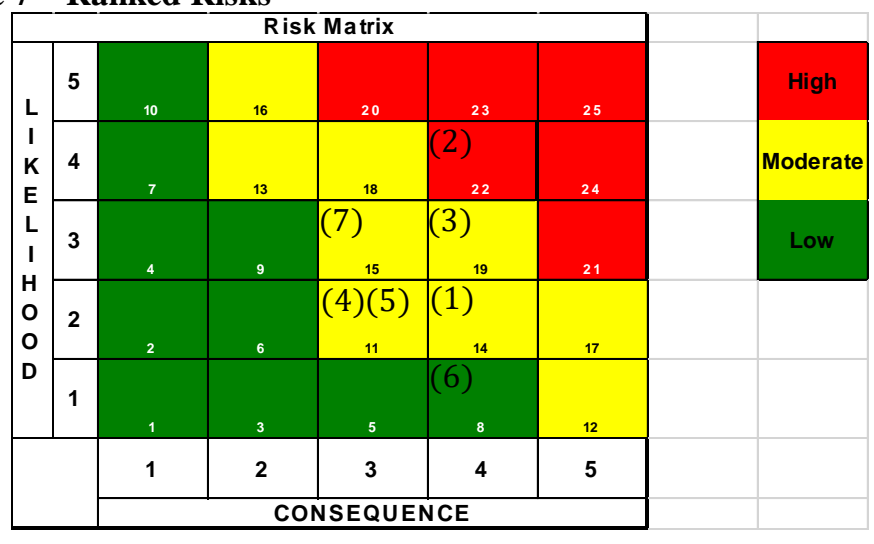

Table 8 - Risks
Consequence

If the cryo-cooler performance drops to the point where the superconductor temperatures rise above about $70 \mathrm{~K}$, the motor will not function correctly

(2) Rotor There is a risk that the Superconducting superconducting rotor

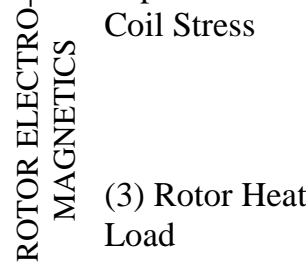
coils will not be able to handle the centrifugal rotor stress field

There is a risk that the rotor heat load will be higher than expected.
The motor will need to be designed at a lower surface speed, reducing power density.

The motor will not reach the temperature needed for superconducting operation
Background

Cryo-coolers are not normally designed to be operated on a spinning platform.
Superconductors are comprised of a large range of material types and it is difficult to characterize their stress limits.

Some of the rotor heat sources are difficult to estimate analytically. Specifically the 2nd and 3rd order eddy current and hysteresis losses 
(4) Rotor There is a risk that the Inconsistent manufacturing Superconducting superconducting rotor will lead to variations in Coil Manufacturing coil will be difficult to manufacture from coil to coil.

(7) Slotless Stator Coil Manufacturing
(5) Slotless Stator Coil Cooling

There is a risk that it If the stator cooling is below will be difficult to cool estimates, the maximum the slotless stator stator current density will be reduced and the maximum power will drop.

(6) Slotless Stator Coil Shear Stress be able to handle the current will be reduced and
There is a risk that the stator will be difficult to manufacture. the maximum power will drop may result in poor coil which may be the dominant heat load in this motor rotor.

Other research groups have completed similar rotors, however we do not have experience in this area.

The design uses a high power slotless stator coil design which is a thick belt of relatively fine conductors bonded by epoxy. It is difficult to transfer heat out of the conductors to the stator backiron effectively.

There is a risk that the If the stator cannot withstand The design uses a high power slotless stator will not the shear load, the maximum

slotless stator coil design which is a thick belt of relatively fine conductors bonded by epoxy. This means that the coil pack needs to directly counter the magnetic forces. In a standard stator coil those forces are largely carried by the stator teeth.

Other industry groups have completed similar slotless stator strength or poor dimensional tolerances coils, however we do not have experience in this area

\section{Stator Design and Risk Reduction Tests}

\section{A. Stator Design}

The HEMM employs a semi-slotless stator, with thin teeth and single turn Litz wire windings. The stator parameters are shown in Table 9, and the stator cross section is shown in Figure 4. The teeth do not serve a significant role electromagnetically, however they do provide a heat removal path and a physical constraint for the stator winding. Since this machine uses superconductors, it is possible to achieve a high air gap magnetic field; as a consequence, the stator windings are exposed to a high fluctuating field, necessitating the use of Litz wire to minimize eddy current losses in the windings. Additionally, in order to keep the output voltage of the machine under $1200 \mathrm{~V}$, a single turn winding will be used. A nine phase configuration was chosen to allow minimization of the harmonic content, and to yield a slight performance benefit compared to a three phase machine.

The stator of the HEMM houses the cooling loop, and functions as the vacuum enclosure for the rotor. HEMM is designed with a direct liquid cooling loop, which circulates from a manifold at the inner surface of one end winding, across the length of the air gap, around the other end winding, back through a series of channels in the backiron, and finally across the outer diameter of the first end winding (Figure 5). The cooling loop passes through the airgap, resulting in a fairly large separation between the stator and rotor. Although the large airgap impacts performance, the penalty is not significant compared to that of a machine with non-superconducting field windings, because the superconducting configuration enables a very high number of amp-turns in a small rotor coil without resistive loss. The vacuum enclosure is incorporated in the stator using a thin wall composite tube. This enclosure maintains vacuum around the superconducting motor rotor, thermally isolates it, and dramatically reduces windage drag losses. 
Table 9. Stator Design

\begin{tabular}{llll}
\hline \hline Parameter & Value & & \\
\hline Type & $\begin{array}{l}\text { Semi } \\
\text { slotless }\end{array}$ & & \\
Iron & & Winding & \\
Inner Diameter & $306 \mathrm{~mm}$ & Number of Phases & 9 \\
Outer Diameter & $377 \mathrm{~mm}$ & Layout & Lap, 2 Layer, Over/Under \\
Stack Height & $125 \mathrm{~mm}$ & Number of Turns & 1 \\
Slots & 108 & Litz Wire & $8 \times 8 \mathrm{~mm}, 6000$ strands x \\
& & Coil Slot Span & $90 \mathrm{AWG}$ \\
Slot Width & $8 \mathrm{~mm}$ & Phase/Group & $6 / 2$ \\
Slot Depth & $19.5 \mathrm{~mm}$ & Offset & \\
Skew & $3.33 \mathrm{degrees}$ & & \\
Cooling & $3.5 \mathrm{~mm}$ & & \\
Channel & & & \\
\hline
\end{tabular}

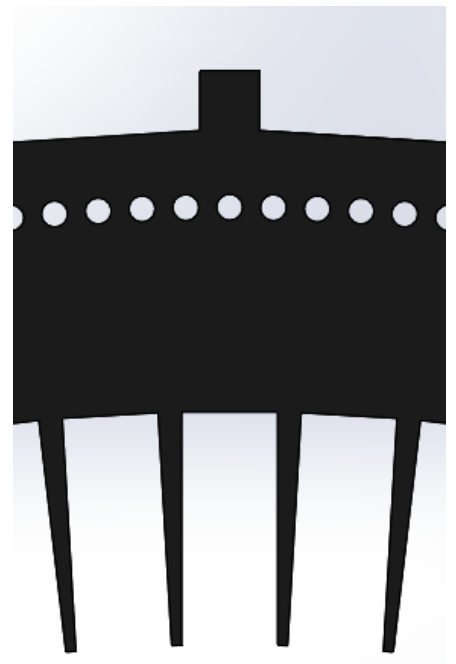

Figure 4. Stator Cross Section

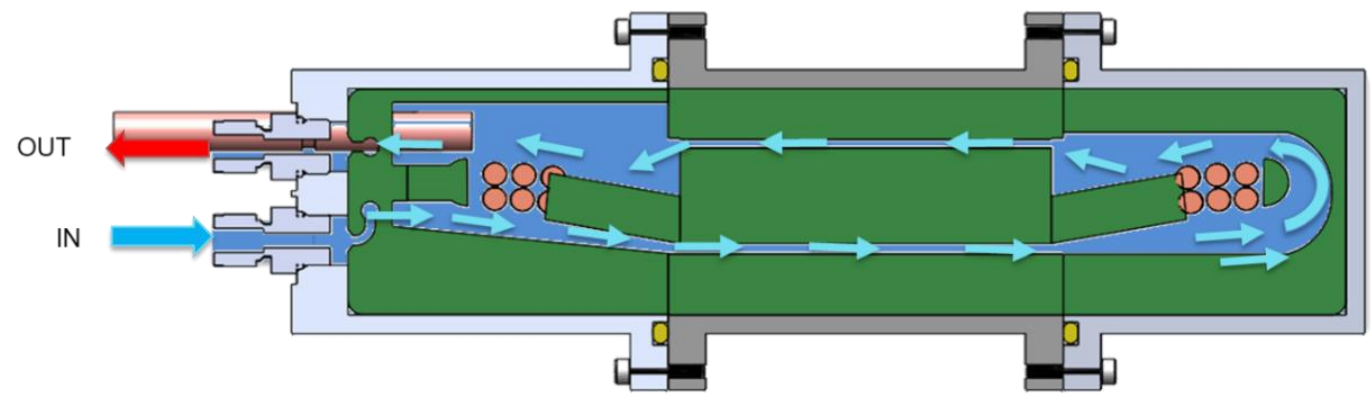

Figure 5. Cooling Loop Path

\section{B. Stator Risk Reduction Effort}

The stator risk reduction effort is focused on the cooling and manufacturing process for the semi-slotless stator. The risk that the slotless stator will not be able to handle the magnetic shear load has been eliminated through the introduction of the semi-slotless design feature. This risk reduction effort included analytical and experimental work; the analytical work consisted of fundamental analysis, semi-empirical methods, and computational fluid dynamics (CFD), while the experimental effort consisted of building and testing a section of the stator.

In order to empirically measure the Litz wire effective thermal conductivity and the cooling fluid convection coefficient, a statorette test section (Figure 6) was built, which comprised approximately one ninth of a complete circumferential stator. A significant effort was made to develop a satisfactory manufacturing process for potting the Litz wire within the semi-slotless stator using high thermal conductivity epoxy. Challenges stemmed from the highly viscous nature of the epoxy, combined with the different scale features between the lamination slot cavities, the wire bundle, and the wire strands (Figure 7). Eventually a method was developed using a combination of temperature profiles, vacuum, and pressure that has achieved the desired combination of low voids and very little excess epoxy on the exterior of the parts.

A number of thermal analysis efforts were conducted to estimate the temperature of the hot spot in the motor. An analytical packing approach method was used to estimate the effective thermal conductivity through and along the Litz wire; the packing factor was based on experimental measurements of sample Litz wires. A resistance network model, which included the iron laminations, the Litz wire, and the surrounding coolant flow, was used for initial estimates of the hotspot temperatures in the stator. Finally, a conjugate heat transfer analysis using a combination of FEA methods was used to estimate hot spot temperatures (Figure 8). The statorette test section temperatures were 
lower than the expected values in the motor, because the test was conducted at DC, so the iron related losses were absent. An interesting feature is that the end turn winding hot spot was found to be higher than the core hot spot in this motor.

Test results were promising and well correlated to modeling results. Tests were conducted between 0 and 500A conducted current, with coolant flow rates between 4.3 and 11.8 LPM. The measured steady state hot spot temperature was significantly below the material limit of $220^{\circ} \mathrm{C}$, as seen in Figure 9; this figure also depicts the measured end winding hot spot temperature estimates as a function of coolant flow rate. Analytical and experimental results showed agreement to within $20^{\circ} \mathrm{C}$ or better throughout the range of current, flow, and coil locations (Figure 10). Table 10 shows the statorette requirements and results which indicate that a positive temperature margin and the required current operating point have been achieved.

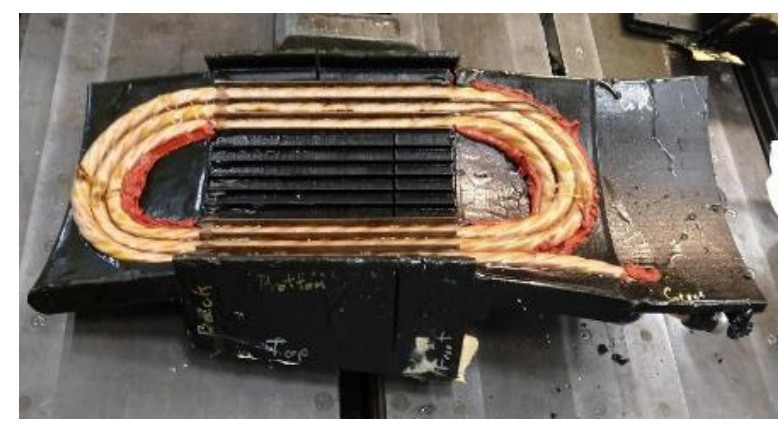

Figure 6. Statorrette Coils

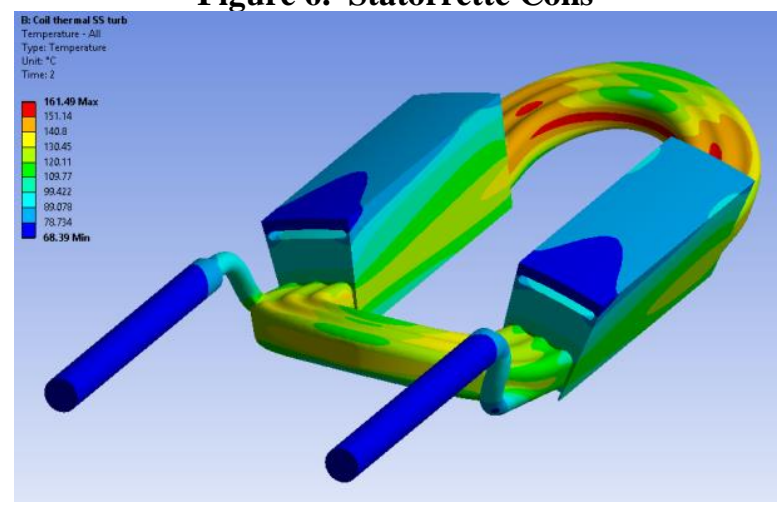

Figure 8. Estimated Winding Temperatures

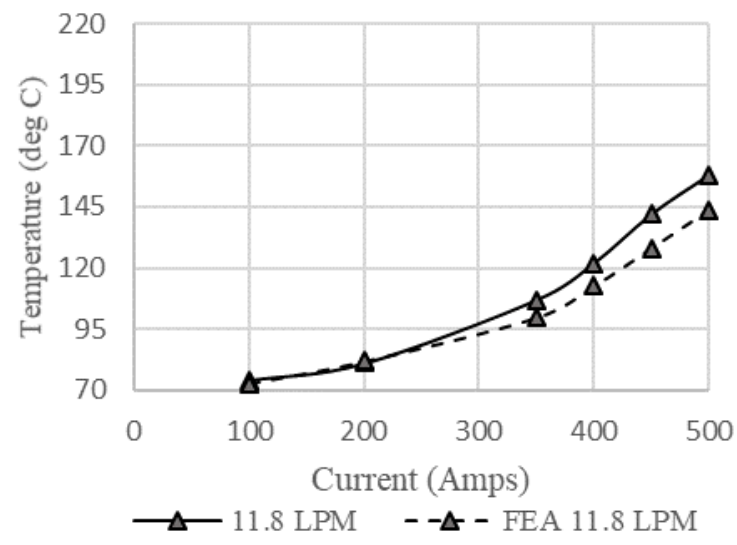

Figure 10. Active area hot spot temperature, experimental result compared to analysis
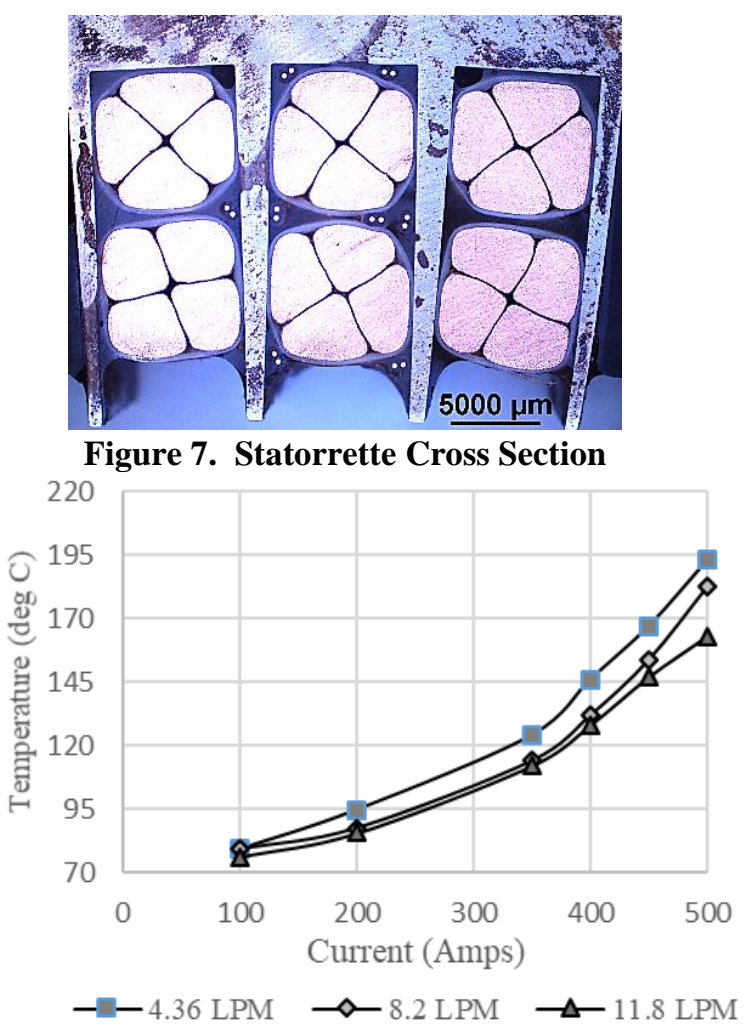

Figure 9. End Turn Hot Spot Temperature vs Current and Coolant Flow Rate

Table 10. Statorette Test Results

\begin{tabular}{lccc}
\hline \hline & Requirement & FEA Estimate & Test Result \\
\hline Condition & $500 \mathrm{~A}$ & $\begin{array}{c}500 \mathrm{~A} @ 11.8 \\
\text { LPM }\end{array}$ & $\begin{array}{c}500 \mathrm{~A} @ 11.8 \\
\text { LPM }\end{array}$ \\
$\begin{array}{l}\text { Hot spot in } \\
\text { Active region }\end{array}$ & $220^{\circ} \mathrm{C}$ & $144^{\circ} \mathrm{C}$ & $158^{\circ} \mathrm{C}$ \\
$\begin{array}{l}\text { Hot spot in end } \\
\text { turn }\end{array}$ & $220^{\circ} \mathrm{C}$ & $161^{\circ} \mathrm{C}$ & $163^{\circ} \mathrm{C}$ \\
\hline
\end{tabular}




\section{Rotor Design and Risk Reduction Tests}

\section{A. Rotor Design}

The HEMM rotor is a twelve pole, non-laminated, cobalt iron rotor, wound with DC superconducting coils. Key rotor parameters are shown in Table 11, and the rotor cross section is shown in Figure 11.

The use of superconducting wires to create a high field in a motor without conduction losses greatly improves the electric machine's performance relative to a system that uses non-superconducting windings. In the HEMM application, the superconductor carries direct current (DC), not alternating current (AC); thus no new superconductor technology needs to be developed, and the conductive losses in the rotor will be near zero. The challenge in the rotor coil design is to minimize mechanical stress and fatigue while maintaining a good electromagnetic circuit and conductive cooling path. Additional factors that limit the maximum current allowed in the superconductor are the operating temperature and field that the superconductor is exposed to. The current density used in the performance estimate was adjusted to include the impact of these two factors, plus margin.

The rotor coil design risks were minimized by limiting the surface speed of the rotor, and by using a relatively mature superconductor-based composite conductor. The surface speed of the HEMM rotor is $100 \mathrm{~m} / \mathrm{s}$, which is one third to one half the surface speed of many high specific power motor designs; in addition to the risk reduction, this lower surface speed and corresponding lower rotor speed provides an additional benefit, as it allows the machine to be directly coupled to a turbofan (when utilized as a generator) or to a propulsor, i.e., a fan or propeller (when used as a motor) without the need for a gearbox. Lower surface speed reduces the stress on the superconductors. The rareEarth barium copper oxide (REBCO) type superconductors have a relatively high superconducting temperature (92K critical temp), and are commercially available in lengths of several hundred meters. This length is sufficient to wind each level of the proposed HEMM rotor coils using a single piece of wire. Although commercially available REBCO composite tapes are relatively mature, the stability in this application (temperature, cyclic magnetic field, and cyclic, multi axial mechanical stress environment) must still be confirmed.

Table 11. Rotor Design

\begin{tabular}{ll}
\hline \hline Parameter & Value \\
\hline Type & DC wound field \\
Inner Diameter & Between 189.4 to $200 \mathrm{~mm}$ \\
Outer Diameter & $300 \mathrm{~mm}$ \\
Length & $125 \mathrm{~mm}$ \\
Number of Poles & 12 \\
Tooth Width & $34 \mathrm{~mm}$ \\
Coil & \\
Rated Current & $51.5 \mathrm{~A}$ \\
Number of Turns & 916 turns per pole \\
Coil Cross Section & $14.9 \mathrm{~mm}$ wide x $16.75 \mathrm{~mm}$ tall \\
Operating condition & $62.8 \mathrm{~K}$ temperature, $2 \mathrm{~T}$ field \\
Conductor & REBCO superconductor $4 \mathrm{~mm} \mathrm{x}$ \\
& $0.065 \mathrm{~mm}$ \\
\hline
\end{tabular}

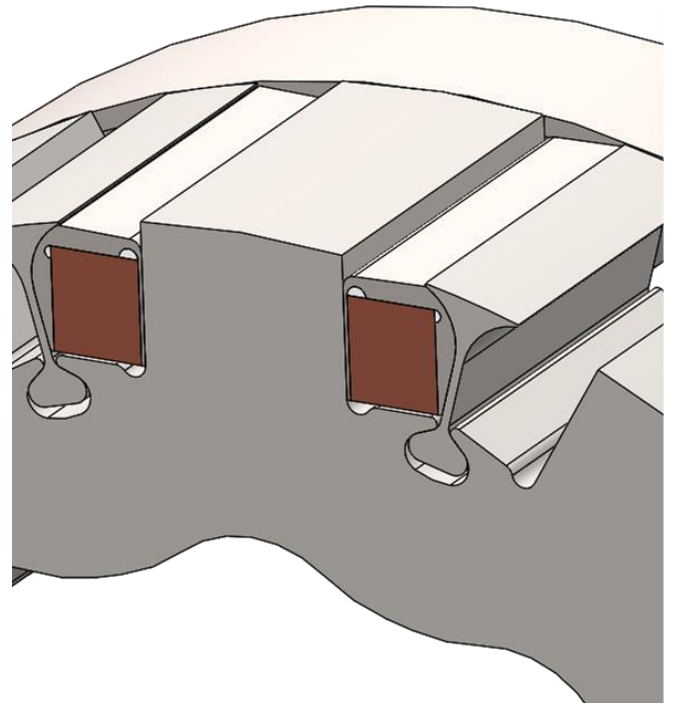

Figure 11. Rotor Cross Section

\section{B. Superconducting Coil Risk Reduction Effort}

The superconducting coil risk reduction will have two phases, static and dynamic testing. The static test activity described herein is intended to establish a manufacturing process for the coils, validate that the coil can be conductively cooled, and show that the coil can sustain thermal cycling.

The superconducting coil manufacturing process steps are: winding, stacking, and installation soldering of jumpers and current leads. A winding fixture, tensioner, and coil spool holder were developed to facilitate assembly. Coils are wound with constant tension in order to maintain sufficient packing. The fixture maintains the proper coil shape and a thin layer of epoxy is applied on the end surface of the coil to keep the layers together when removed. Low temperature solder (52\%In, $48 \% \mathrm{Sn}$ ) and mild $\mathrm{ZnCl} 2$ solution is are used to connect the coils to the coil jumpers and copper terminal blocks. High temperature solder $(\% 96.5,3.0 \% \mathrm{Ag}, 0.5 \% \mathrm{Cu})$ is used to attach the current leads to the 
terminal blocks. The fixturing used for superconducting coil winding is shown in Figure 12, and a resulting four layer superconducting coil is shown. A subscale mock up is shown in Figure 13.

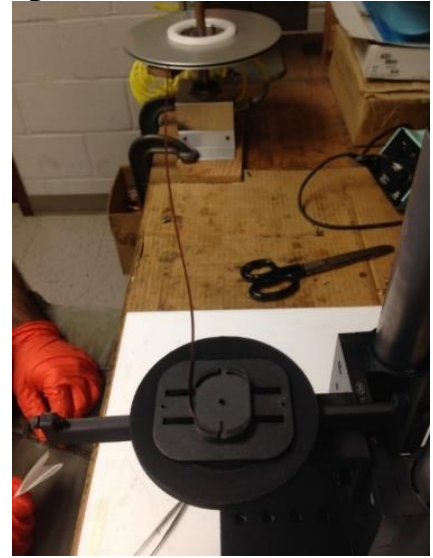

Figure 12. Superconducting coil winding

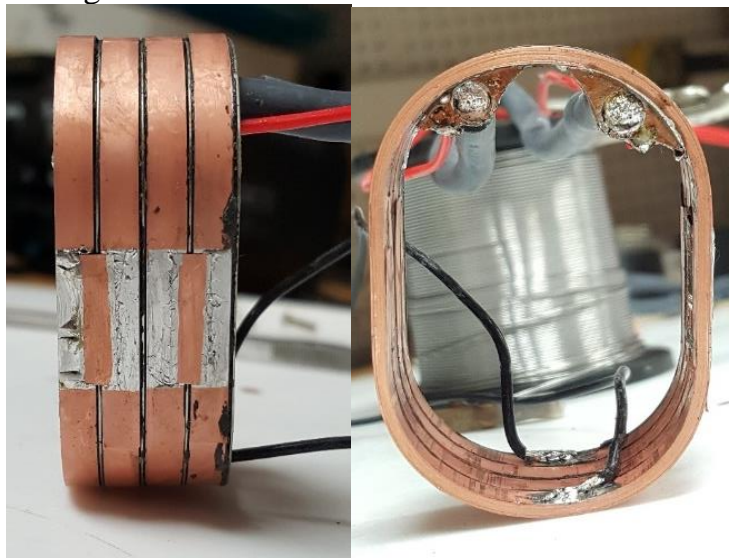

Figure 13. Four Layer Superconducting Coil

Thermal conductivity through the coil is an important parameter. Analytical estimates were made to determine the impact of the cross coil thermal conductivity on coil temperature (Table 12), and to estimate this as a function of wire to wire thermal contact resistance (Figure 14).

Table 12. Coil Temperature as a Function of Coil Thermal Conductivity

\begin{tabular}{ll}
\hline \hline $\begin{array}{l}\text { Coil Thermal Conductivity } \\
(\mathrm{W} / \mathrm{m} / \mathrm{K})\end{array}$ & $\begin{array}{l}\text { Maximum Coil Temperature } \\
(\mathrm{K})\end{array}$ \\
\hline 0.1 & 64.0 \\
1.0 & 60.7 \\
5.0 & 58.8 \\
8.9 & 58.4 \\
\hline
\end{tabular}

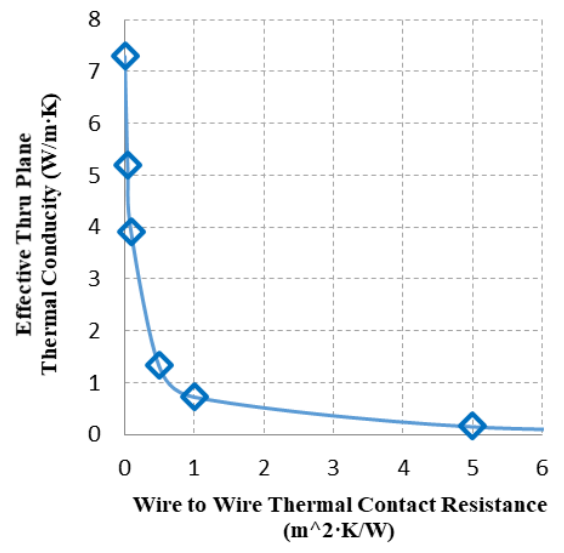

Figure 14. Through Plane Effective Thermal Conductivity

Subscale test coils were thermally cycled, and the critical current was measured before and after cycling to measure coil integrity. Cycling tests were conducted in a rig which allowed the coil to be immersed in liquid nitrogen until reaching steady state, then removed to come back up to ambient temperature (Figure 15). Current was supplied using a linear amplifier, and coil currents and voltages were measured using a four wire technique and a digital multimeter.

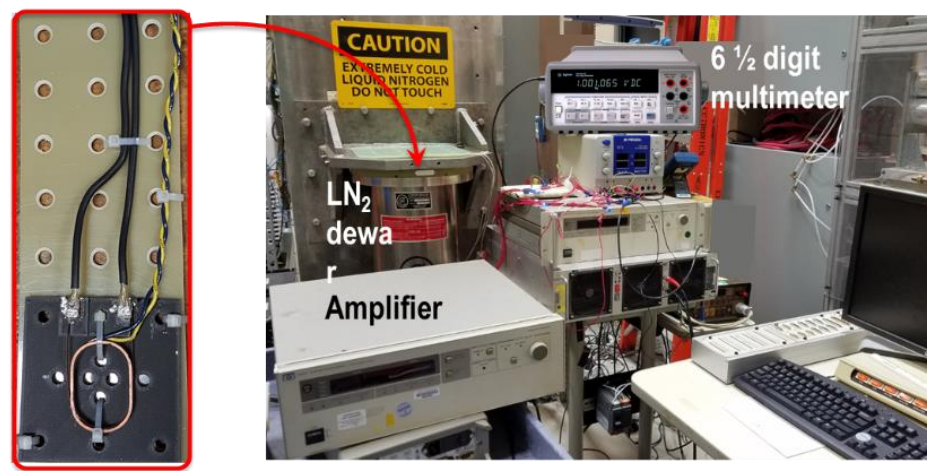

Figure 15. Superconducting coil test rig for cycle testing

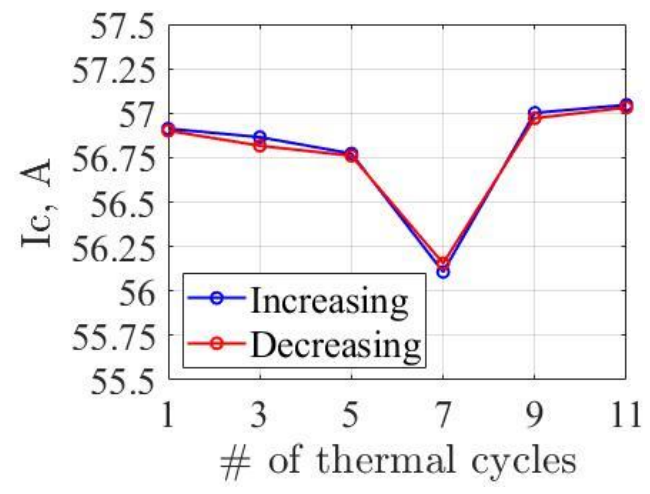

Figure 16. Critical Current vs Cycles 
Test results show that the subscale prototype coils maintain a consistent current carrying capacity through ten thermal cycles. Further testing will be done, using full scale coils and higher numbers of thermal cycles.

\section{Cryocooler Risk Reduction Effort}

In the HEMM application the cryocooler must rotate at high speed, which is atypical. This rotation might cause performance issues, so a combination of analytical and experimental risk reduction efforts are being performed. A key element of our cryocooler design are flexure springs that are used as bearings for the linear motor that drives the cryocooler piston (Figure 17). This design was especially challenging since the oscillating amplitude is quite large comparted to the flexure outer diameter. In addition, it must function both at rest and at 6800 RPM. We have found a design made of high-fatigue-strength compressor valve steel, which we believe meets the combined criteria of stress (Figure 18) and stiffness. Stress needed to be kept below the high cycle fatigue limit of the material. The stiffness, which sets the oscillation frequency of the cryocooler, can be seen as a function of operating speed and flexure displacement in Figure 19. The linear motor of the cryocooler is being manufactured for the next set of risk reduction tests, which will consist of running at its maximum oscillation amplitude for approximately $10^{7}$ cycles, first at 0 RPM and then at 6800 RPM.

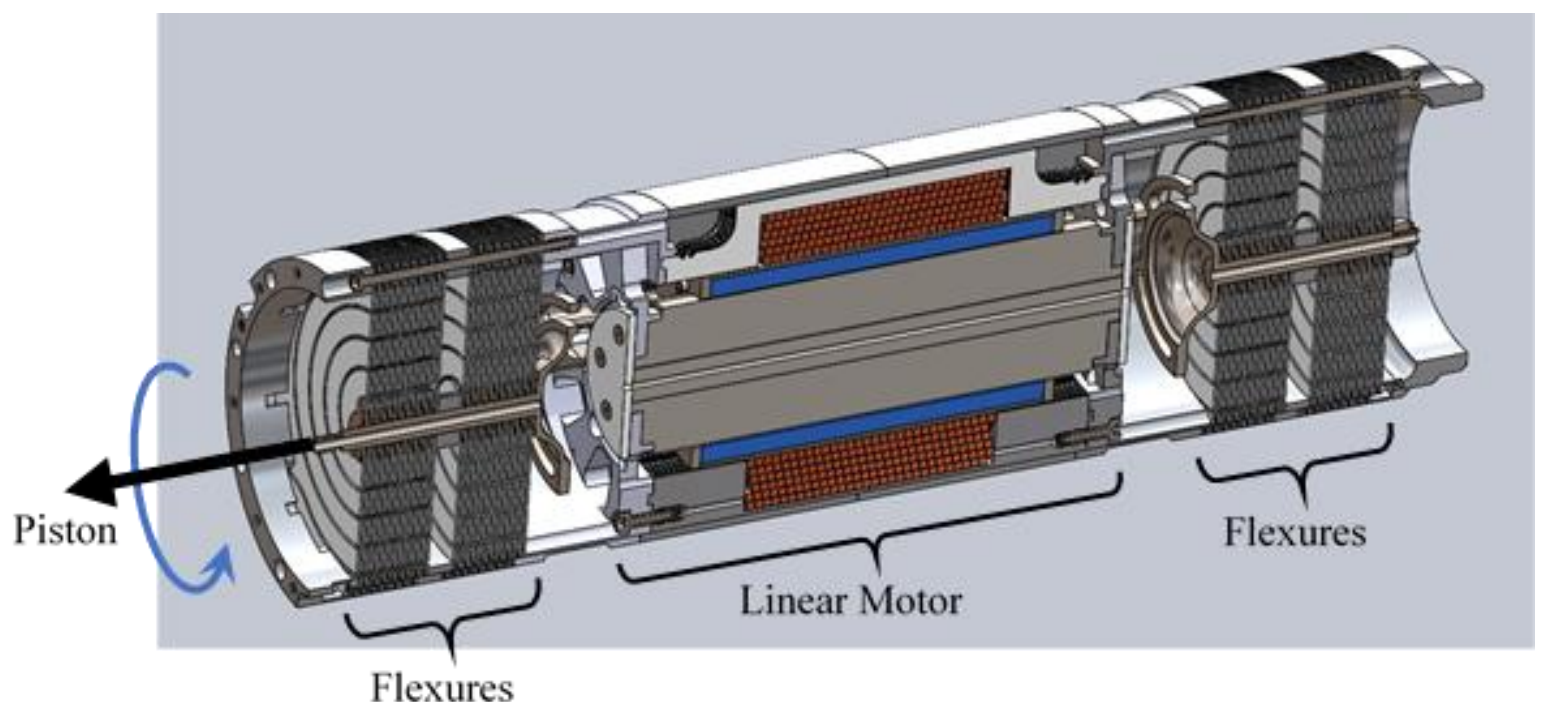

Figure 17. Cryocooler Linear Motor

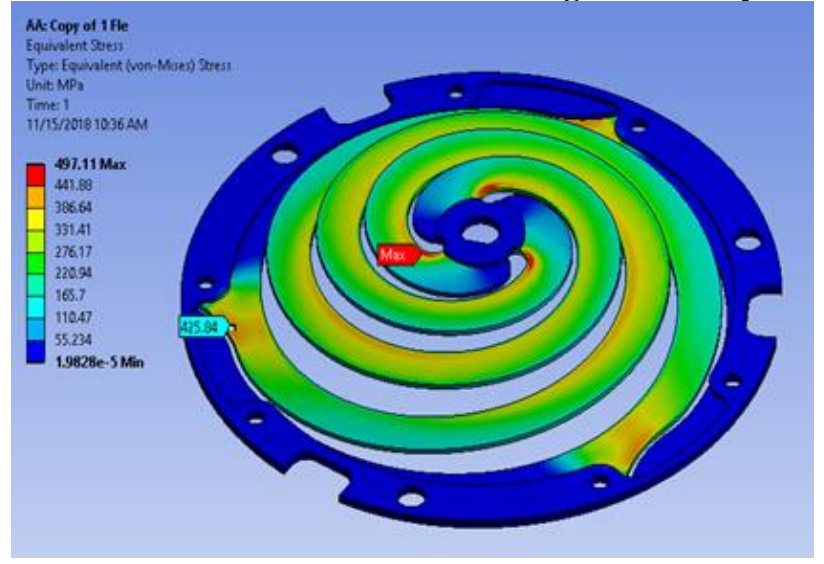

Figure 18. Flexure Stress at Maximum Displacement and Speed

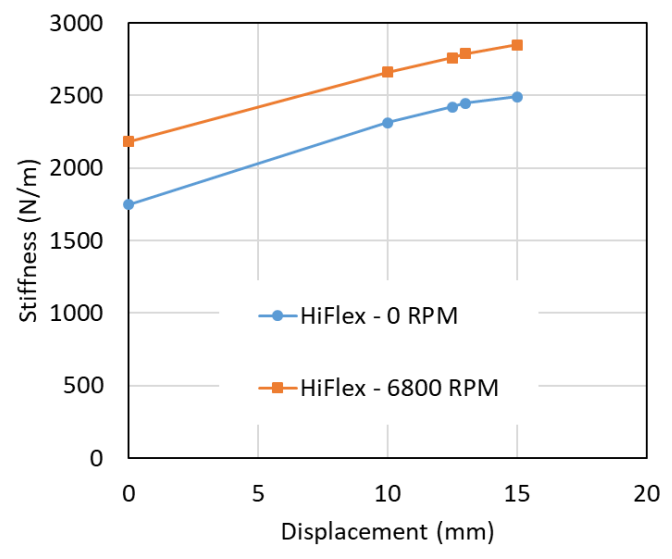

Figure 19. Flexure Stiffness vs. Speed 


\section{Summary}

The High Efficiency Megawatt Motor (HEMM) being designed at NASA Glenn Research Center is a wound field partially superconducting machine. The goal of this effort is to develop an electrical machine with efficiency greater than $98 \%$, and specific power when ratioed to electromagnetic mass greater than $16 \mathrm{~kW} / \mathrm{kg}$. A design has been completed, and electromagnetic analysis demonstrates that it will achieve the required performance if critical design aspects close thermally and structurally. Those design aspects impact the maximum continuous stator current, the maximum continuous rotor current, and the air gap. Using a risk based approach, key component tests were identified for the stator, superconducting coils, and cryocooler. The tests completed so far have demonstrated the required performance in the aspects under consideration, however further component testing is required to retire the risks outlined in the risk matrix. More detailed information on the component tests completed so far can be found in references 8-10.

\section{Acknowledgments}

This work is sponsored by the NASA Advanced Air Transportation Technologies Project/Hybrid Gas Electric Subproject managed by Amy Jankovsky, and the Convergent Aeronautics Solutions Project/High Efficiency Electrified Aircraft Thermal Research (HEATheR) activity. The work is performed at NASA Glenn Research Center. The team is managed by Yaritza De Jesus-Arce with Ralph Jansen as the technical lead. Team members include in alphabetical order Aaron Anderson, Thomas Balogas, Dr. Kirsten Duffy, Dr. Rodger Dyson, Don Fong, Hardy Hartman, Hashmatullah Hasseeb, George Horning, Frank Gaspare, Scott Metzger, Wesley Miller, Paul Passe, Malcolm Robbie, Dr. Justin Scheidler, Andrew Smith, Erik Stalcup, Will Sixel, Casey Theman, Tom Tallerico, William Torres, and Dr. Andrew Woodworth.

\section{References}

${ }^{1}$ Welstead, J., and Felder, J. L., "Conceptual Design of a Single-Aisle Turboelectric Commercial Transport with Fuselage Boundary Layer Ingestion," 54th AIAA Aerospace Sciences Meeting, AIAA, Reston, VA, 2016.

${ }^{2}$ Jansen, R. H., De Jesus-Arce, Y., Kascak, P. E., Dyson, R. W., Woodworth, A. A., Scheidler, J. J., Edwards, R. D., Stalcup, E. J., Wilhite, J. M., Duffy, K. D., Passe, P. J., McCormick, S. P., "High Efficiency Megawatt Motor Conceptual Design," 2018 Joint Propulsion Conference, AIAA Propulsion and Energy Forum, AIAA 2018-4699, Cincinnati, Ohio, 2018.

${ }^{3}$ Jansen, R. H., Brown, G. V., Felder, J. L., and Duffy, K. P., "Turboelectric Aircraft Drive Key Performance Parameters and Functional Requirements," 51st AIAA/SAE/ASEE Joint Propulsion Conference, AIAA Propulsion and Energy Forum, AIAA 2015-3890, Reston, VA, 2015.

${ }^{4}$ Jansen, R. H., Duffy, K. P., and Brown, G. V., "Partially Turboelectric Aircraft Drive Key Performance Parameters," 53rd AIAA/SAE/ASEE Joint Propulsion Conference, AIAA Propulsion and Energy Forum, AIAA 20174702, Atlanta, GA, 2017

${ }^{5}$ Jansen, R. H., Kascak, P. E., Dyson, R. W., NASA Glenn Research Center, Cleveland, OH, U.S. Provisional Patent, "Wound field synchronous machine", filed June 2016.

${ }^{6}$ Jansen, R. H., Kascak, P. E., Dyson, R. W., NASA Glenn Research Center, Cleveland, OH, U.S. Provisional Patent, "Wound field synchronous machine", filed June 2017.

${ }^{7}$ Jansen, R. H., Kascak, P. E., Dyson, R. W., NASA Glenn Research Center, Cleveland, OH, U.S. Provisional Patent, "Wound field synchronous machine", filed October 2017.

${ }^{8}$ Woodworth, A. A., Smith, A. D., Sixel, W. R., Edwards, R. D., Jansen, R. H., McCormick, S. P., Robbie, M. G., Szpak, G. M., Naghipour P., Shin, E., "Thermal Analysis of Potted Litz Wire for High Power Density Aerospace Electric Machines,” 2019 AIAA/IEEE Electric Aircraft Technologies Symposium, Indianapolis, Indiana, 2019. 
${ }^{9}$ Scheidler, J. J., Tallerico, T. F., Miller, W. A., Torres, W., "Progress Toward the Critical Design of the Superconducting Rotor for NASA's 1.4 MW High-Efficiency Electrical Machine," 2019 AIAA/IEEE Electric Aircraft Technologies Symposium, Indianapolis, Indiana, 2019.

${ }^{10}$ Dyson, R. W., Jansen, R. H., Duffy, K. D., Passe, P. J., "High Efficiency Megawatt Machine Rotating Cryocooler Conceptual Design," 2019 AIAA/IEEE Electric Aircraft Technologies Symposium, Indianapolis, Indiana, 2019. 